\title{
Technical note: Validation of methodology for characterization of feeding behavior in dairy calves
}

\author{
E. K. Miller-Cushon and T. J. DeVries ${ }^{1}$ \\ Department of Animal and Poultry Science, University of Guelph, Kemptville Campus, 830 Prescott Street, Kemptville, ON, K0G 1J0, Canada
}

\begin{abstract}
Time sampling techniques are useful in collecting feeding behavior data because they minimize the time required for observation. Instantaneous recording is often used in the collection of feeding behavior data for dairy calves; however, the recording intervals used vary widely and it is unclear what minimum interval is necessary to yield accurate data. The objective of this study was to validate data obtained using instantaneous recording of feeding behavior of dairy calves across a range of time intervals with data obtained from continuous recording. Ten Holstein bull calves were observed continuously using time-lapse video for $3 \mathrm{~d}$ during the milk-feeding period while they were fed milk ad libitum and for $3 \mathrm{~d}$ post-milk-weaning while they consumed solid feed. Feeding behavior data obtained from continuous recording were compared with data obtained from instantaneous recording at intervals ranging from $15 \mathrm{~s}$ to $10 \mathrm{~min}$. As expected, the strength of linear association between behavior measures obtained from continuous recording and instantaneous recording decreased with increasing recording interval. The relationship varied between feeding behavior measures; feeding time was represented well $\left(\mathrm{R}^{2}>0.76\right)$ by instantaneous recording at up to 5 -min intervals, but a strong linear association of meal frequency and meal time $\left(\mathrm{R}^{2}\right.$ $>0.8$ ) required intervals no greater than $1 \mathrm{~min}$ and 30 $\mathrm{s}$, respectively. The relationship between feeding behavior measures obtained from continuous recording and recording at different intervals was similar in both periods; however, sensitivity of time sampling data across recording intervals was greater during the milk-feeding period. Sensitivity was low in both periods $(<0.7$ with scanning intervals as short as $1 \mathrm{~min}$ ), indicating that instantaneous recording may not represent within-meal feeding behavior well. Instantaneous recording can provide accurate calf feeding behavior data if the recording interval is sufficiently short.
\end{abstract}

Received March 31, 2011.

Accepted August 25, 2011.

${ }^{1}$ Corresponding author: tdevries@uoguelph.ca
Key words: dairy calf, feeding behavior, time sampling, instantaneous recording

\section{Technical Note}

Characterizing feeding patterns of dairy calves is important because feeding behavior is related to health and welfare of calves. Differences in feeding patterns of calves can be an indicator of disease onset (Svensson and Jensen, 2007), feeding motivation (de Paula Vieira et al., 2008), competition in a social environment (Jensen and Budde, 2006), and freedom to perform natural meal patterns (Jensen, 2009). Thus, feeding patterns are an important behavioral measure in many nutrition and management studies.

Feeding behavior may be measured through a variety of methods, including live observation, observation from video, and automated measurement devices. Automated measurements are becoming more common; however, they often require that animals be housed in groups (e.g., automatic milk-feeding systems; Svensson and Liberg, 2006). In cases where calves are housed individually or in small groups, direct observation (live or from video) is often the only method of assessing feeding behavior. Live observation is a viable option when it is necessary to monitor behavior for only a short period (e.g., for a period after feeding; Rushen and de Passillé, 1995). However, live observation is often not feasible for the longer periods required to characterize diurnal feeding patterns exhibited by cattle. Thus, video recordings are often used for reviewing feeding behavior throughout the day.

Instantaneous recording is a method of time sampling used to collect more data than would be possible with continuous recording in a reasonable amount of time. With this method, an instantaneous scan is performed at a set interval of time and a record is made of whether or not the behavior is occurring (Martin and Bateson, 2007). Instantaneous recording is common in studies focusing on feeding behavior of dairy cattle. A disparity in viewpoints on appropriate recording intervals for determination of behavior calves is evident in the literature; frequently utilized intervals range from 1 min or less (Jensen and Budde, 2006; de Paula Vieira 
et al., 2008) to $10 \mathrm{~min}$ (Gibb et al., 2000; Chua et al., 2002; Haley et al., 2005).

Validation of instantaneous recording is necessary to ensure accuracy of data. For example, 10-min recording intervals have been found to provide sufficient accuracy for the determination of feeding time in lactating cows (Endres et al., 2005) and group-housed dairy heifers (Kitts et al., 2011). Instantaneous recording is most accurate when the interval is short relative to the duration of the observed behavior (Mitlohner et al., 2001; Martin and Bateson, 2007); thus, calf feeding time may not be represented well by the same recording intervals used for adult cattle because calf meals may be shorter in duration than adult cattle meals. Despite the frequent use of instantaneous recording in the characterization of calf solid feed or milk intake time, there is a paucity of data offering validation of this time sampling method for assessing feeding behavior of calves. Further, instantaneous recording over a period is often used to provide a single value, based on the number of positive scans (e.g., total daily feeding time; Kitts et al., 2011). However, with an appropriately short time sampling interval, the accuracy of the data collected should be sufficient to characterize diurnal feeding behavior, including meal frequency and meal duration, in addition to total daily feeding time.

Therefore, the objective of this study was to compare calf feeding behavior data obtained from continuous recording with data obtained from a variety of instantaneous recording intervals. The hypothesis was that a small range of appropriate intervals would be apparent, depending on the feeding behavior measure of interest, allowing researchers to obtain sufficiently accurate calf feeding behavior data with minimized labor.

For this study, 20 Holstein bull calves were housed within individual pens $(1.2 \times 1.8 \mathrm{~m}$; width $\times$ depth $)$ at the University of Guelph Kemptville Campus Dairy Education and Research Centre (Kemptville, ON, Canada) and were managed according to the standard operating procedures of this research station, in accordance with guidelines set by the Canadian Council on Animal Care (2009). As part of another study, calves were randomly assigned to different milk feeding levels: (1) ad libitum milk feeding or (2) restricted milk feeding, at a rate of $5 \mathrm{~L} / \mathrm{d}$. Calves were fed $22 \% \mathrm{CP}$ and $18 \%$ fat Shur-Gain High Performance Milk Replacer (Nutreco Canada Inc., Guelph, ON, Canada), mixed as indicated at a rate of $150 \mathrm{~g} / \mathrm{L}$ of water. Milk was provided via an artificial teat attached to a line fitted to a one-way valve, running from a milk bucket situated on the outside of the pen. For calves fed ad libitum, fresh milk replacer was delivered at $0800 \mathrm{~h}$, with the amount replenished at $1600 \mathrm{~h}$ as required to ensure unrestricted intake. Calves on the restricted milk feed- ing level received their daily allotment in 2 feedings at 0800 and $1600 \mathrm{~h}$. Calves were weaned off milk during wk 7 . On the first day of wk 8 , a complete pelleted diet (Shur-Gain High Fiber 20\% Heifer Ration, Nutreco Canada Inc.) was offered ad libitum. Calves remained on the study, receiving the pelleted diet, for an additional $7 \mathrm{wk}$.

The behavior of all calves was recorded continuously throughout the study using 8 color video cameras (Day/Night Camera, model no. WV-CP504; Panasonic, Osaka, Japan) fitted with an F0.95/2.8- to 8-mm lens (Fujinon CCTV lens, Fuji, Tokyo, Japan). Cameras were connected to a digital video recorder (Digital Disk Recorder, model no. WJ-HD616K, Panasonic) set to record at 15 images/s. Cameras were positioned above the pens such that each individual pen was fully visible from one of the cameras (placed approximately $2 \mathrm{~m}$ in front of the pens and $4 \mathrm{~m}$ from the pen floor). Four red lights $(100 \mathrm{~W})$ were spaced evenly between cameras and placed on a timer to provide enough light to record during nighttime hours.

Calves were observed for a period during milk feeding as well as after weaning, once they were consuming only solid feed. During the milk-feeding period, a subset of 10 calves (only calves fed milk ad libitum) were observed continuously from recorded video for 3 d during wk 6 (the week before weaning). The start and end of all occurrences of milk feeding were recorded; this behavior was defined as taking place when a calf's mouth was closed on the teat. After weaning, a subset of 10 calves (evenly divided between calves that had been assigned to the restricted milk feeding level and calves that had been assigned to the ad libitum milk feeding level) was observed continuously from recorded video for $3 \mathrm{~d}$ during wk 14 (7 wk after weaning). The start and end of all occurrences of feeding were recorded, with feeding defined as a calf's head lowered in the feed bucket.

Feeding start and end times obtained from continuous recording from video was used to extrapolate data that would have been obtained from the same period using instantaneous recording at the following intervals: $15 \mathrm{~s}, 30 \mathrm{~s}, 1 \mathrm{~min}, 2 \mathrm{~min}, 3 \mathrm{~min}, 4 \mathrm{~min}, 5 \mathrm{~min}, 6 \mathrm{~min}$, and $10 \mathrm{~min}$. To assess diurnal behavior from data obtained using instantaneous recording, each positive scan in the data set was assigned a block of time equivalent to the sampling interval to approximate behavior throughout the day. Comparisons of data obtained from continuous recording and instantaneous recording at different intervals were performed for individual calves by chi-squared $2 \times 2$ contingency tables (feeding or not feeding for each second of the day, as determined from continuous video and as estimated by different instantaneous recording intervals) using SAS software (SAS Institute, 2008). These data were also used to calculate 
sensitivity (likelihood that moments of feeding identified by continuous recording were also identified by instantaneous recording), specificity (likelihood that moments not feeding identified by continuous recording were identified by instantaneous recording), and predictability (likelihood that moments of feeding recorded by instantaneous recording were also identified by continuous recording).

For a subset of the recording intervals $(15 \mathrm{~s}, 30 \mathrm{~s}$, $1 \mathrm{~min}, 2 \mathrm{~min}, 5 \mathrm{~min}$, and $10 \mathrm{~min}$ ), meal analysis was performed. Meal criteria were determined from $3 \mathrm{~d}$ of data for individual calves in each period and for each recording interval using a software package (MIX 3.1.3; MacDonald and Green, 1988) that fits a mixture of normal distributions to the distributions of $\log _{10}$-transformed time intervals between moments of feeding. As described by DeVries et al. (2003), the meal criterion is determined from these modeled distributions as the time point at which the distribution curve of inter-meal intervals intersects the distribution curve of intra-meal intervals. Meal criteria determined from different recording intervals were compared using the MIXED procedure in SAS (SAS Institute, 2008).

For those scanning intervals that allowed for the determination of meal criteria, daily meal frequency for each calf was determined by counting the number of intervals between visits to the feed pail that exceeded the meal criterion. Daily meal time was calculated as the sum of all recorded feeding time and all nonfeeding time periods shorter than the meal criterion. Daily feeding time, meal time, and meal frequency data determined using different instantaneous recording intervals were summarized by calf in both time periods (averaged across $3 \mathrm{~d}$ of observation) and compared with corresponding values determined from continuous recording using linear regression with the REG procedure (SAS Institute, 2008). Tests for whether the slope and intercept differed from 1 and 0, respectively, were performed, and coefficients of determination were generated from these regressions.

A visual comparison of feeding times collected from continuous recording and feeding times as estimated from instantaneous recording at intervals of $30 \mathrm{~s}$ and $60 \mathrm{~s}$ is presented in Figure 1. A 20-min period immediately following feed delivery in the postweaning period is shown for the calf whose instantaneous recording data had the strongest relationship with continuous data according to the chi-squared test ( $\mathrm{phi}=0.75$ on average across both scanning methods) and for the calf whose data had the weakest relationship ( $\mathrm{phi}=0.38$ on average).

Meal criteria calculated for each time interval in both periods are reported in Table 1 (averaged across calves). Data obtained from instantaneous recording at

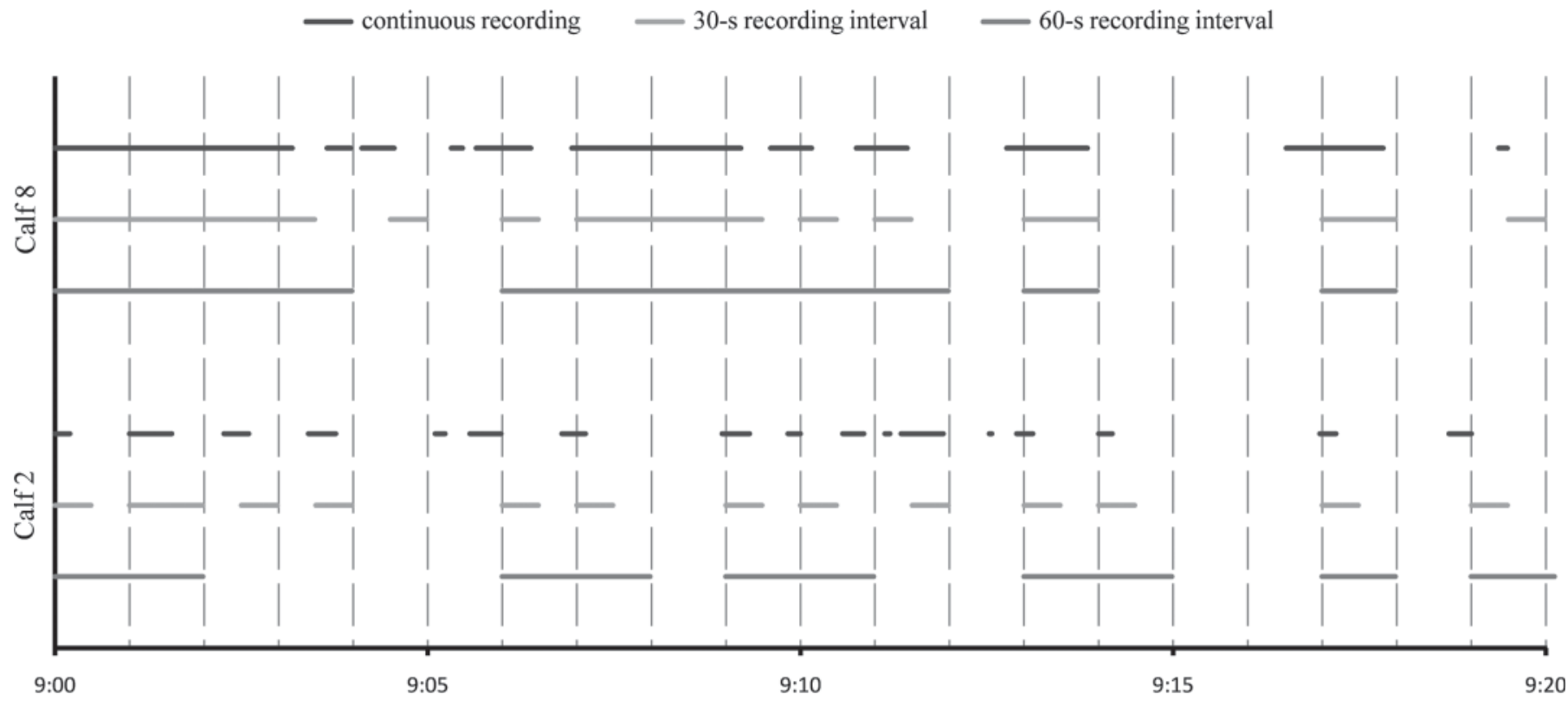

Time (h:mm)

Figure 1. Feeding time for 20 min following feed delivery time for 2 calves postweaning, as collected from continuous recording and as estimated by instantaneous recording at time intervals of $30 \mathrm{~s}$ and $60 \mathrm{~s}$. The 2 calves illustrate the strongest association (calf 8 ; phi $=0.80$ for 30 $\mathrm{s}$ and 0.70 for $60 \mathrm{~s}$, where phi $=\chi^{2}$ phi coefficient) and weakest association (calf 2 ; phi $=0.46$ for $30 \mathrm{~s}$ and 0.30 for $60 \mathrm{~s}$ ) for the comparisons between continuous recording and instantaneous recording. Vertical dashed lines represent 1-min marks. 
Table 1. Meal criteria ${ }^{1}$ (min) determined from data obtained using different instantaneous recording intervals (mean \pm SD)

\begin{tabular}{lccccc}
\hline & & \multicolumn{3}{c}{ Time sampling interval } \\
\cline { 3 - 6 } Meal criteria & $\begin{array}{c}\text { Continuous } \\
\text { observation }\end{array}$ & $15 \mathrm{~s}$ & $30 \mathrm{~s}$ & $1 \mathrm{~min}$ & $2 \mathrm{~min}$ \\
\hline Milk feeding $^{2}$ & $15.6 \pm 9.9$ & $14.7 \pm 10.4$ & $15.0 \pm 7.2$ & $14.9 \pm 10.1$ & $20.6 \pm 10.0$ \\
Postweaning $^{3}$ & $12.3 \pm 2.8$ & $11.9 \pm 2.9$ & $11.9 \pm 3.7$ & $13.4 \pm 2.1$ & $20.1 \pm 6.7$ \\
\hline
\end{tabular}

${ }^{1}$ Meal criteria were determined for individual calves through analysis of cumulative data from $3 \mathrm{~d}$ of observation. Reported values are averaged across 10 calves in each time period.

${ }^{2}$ Calves individually observed for the first $3 \mathrm{~d}$ of wk 6 of the milk-feeding period.

${ }^{3}$ Calves individually observed for the first $3 \mathrm{~d}$ of wk 14 .

10-min intervals did not provide sufficient intra-meal interval frequencies to allow a model to be fitted; thus, it was not possible to determine meal information from these data. Determination of meal criteria from instantaneous recording at intervals of $5 \mathrm{~min}$ and less was possible; however, cumulative data from less than $3 \mathrm{~d}$ of observation, as used in this study, may not provide sufficient information for determination of meal criteria when recording intervals approaching $5 \mathrm{~min}$ are used. Meal criteria were not significantly different across periods.

Meal characteristics as determined by a range of instantaneous recording intervals are reported alongside linear regression results for data collected in the milk-feeding period (Table 2) and in the postweaning period (Table 3 ). The linear relationship between feeding behavior data obtained through instantaneous and continuous recording became weaker with less frequent recording. During both periods, feeding time was most strongly associated at longer intervals compared with other feeding characteristics. Daily feeding time averaged across calves was similar between scanning intervals, possibly due to a compensatory effect of longer instantaneous recording intervals. As scanning intervals increase, occurrences of feeding are more likely to be missed; however, a larger block of feeding time was assigned to a positive scan, which may compensate for missed occurrences of feeding.

Meal time and meal frequency, as obtained through instantaneous recording, decreased substantially on average with increasing recording interval in both periods. Although recording at intervals of 1 min captured $89 \%$ of milk meals in the milk-feeding period and $94 \%$ of solid feed meals in the postweaning period, increasing the interval to 2 min resulted in $10 \%$ fewer meals reported. Similar inaccuracies in meal time were also seen with increasing recording interval; 2-min scans reported only $77 \%$ of meal time on average in the milkfeeding period and $69 \%$ of meal time on average in the postweaning period.

Table 2. Feeding behavior data ${ }^{1}$ and regression analysis ${ }^{2}$ from data collected in the milk-feeding period ${ }^{3}(\operatorname{mean} \pm \mathrm{SD})$

\begin{tabular}{|c|c|c|c|c|c|c|c|}
\hline Item & $\begin{array}{c}\text { Continuous } \\
\text { recording }\end{array}$ & \multicolumn{6}{|c|}{ Time sampling interval } \\
\hline $\mathrm{R}^{2}$ & - & 0.98 & 0.95 & 0.93 & 0.90 & 0.76 & 0.002 \\
\hline Intercept & - & $1.2 \pm 1.4$ & $-0.3 \pm 2.6$ & $2.9 \pm 2.7$ & $4.0 \pm 2.6$ & $3.3 \pm 5.3$ & $30 \pm 12.2^{*}$ \\
\hline Slope & - & $1.0 \pm 0.05$ & $1.0 \pm 0.09$ & $0.91 \pm 0.09$ & $0.89 \pm 0.09$ & $0.90 \pm 0.2$ & $-0.06 \pm 0.4^{*}$ \\
\hline $\mathrm{R}^{2}$ & - & 0.98 & 0.94 & 0.74 & 0.42 & 0.02 & - \\
\hline Intercept & - & $-1.8 \pm 2.4$ & $5.9 \pm 3.6$ & $15.6 \pm 5.3^{*}$ & $21.6 \pm 6.5^{*}$ & $26.6 \pm 9.4^{*}$ & - \\
\hline Slope & - & $1.0 \pm 0.05$ & $0.78 \pm 0.07$ & $0.48 \pm 0.1^{*}$ & $0.3 \pm 0.1^{*}$ & $0.08 \pm 0.18^{*}$ & - \\
\hline \multicolumn{8}{|l|}{ Meal frequency } \\
\hline Meals (no./d) & $6.9 \pm 2.6$ & $6.8 \pm 2.7$ & $6.6 \pm 2.7$ & $6.0 \pm 2.0$ & $5.4 \pm 1.5$ & $4.2 \pm 1.4$ & - \\
\hline $\mathrm{R}^{2}$ & - & 0.99 & 0.93 & 0.84 & 0.71 & 0.18 & - \\
\hline Intercept & - & $-0.4 \pm 0.3$ & $-0.4 \pm 0.7$ & $1.0 \pm 0.8$ & $1.9 \pm 0.8 \dagger$ & $2.6 \pm 1.3 \dagger$ & - \\
\hline
\end{tabular}

${ }^{1}$ Feeding behavior data averaged across 10 calves and $3 \mathrm{~d}$.

${ }^{2}$ Regression analysis performed on data summarized by calf over $3 \mathrm{~d}$ of observation.

${ }^{3}$ Calves individually observed for the first $3 \mathrm{~d}$ of wk 6 of the milk-feeding period.

*Intercept values are different from $0(P<0.05)$ and slope values are different from $1(P<0.05)$; †intercept values tend to be different from 0 $(P<0.10)$ and slope values tend to be different from $1(P<0.10)$. 
Table 3. Feeding behavior data ${ }^{1}$ and regression analysis ${ }^{2}$ from data collected in the post-weaning period ${ }^{3}(\operatorname{mean} \pm \mathrm{SD})$

\begin{tabular}{|c|c|c|c|c|c|c|c|}
\hline Item & $\begin{array}{l}\text { Continuous } \\
\text { recording }\end{array}$ & \multicolumn{6}{|c|}{ Time sampling interval } \\
\hline \multicolumn{8}{|l|}{ Feeding time } \\
\hline $\mathrm{R}^{2}$ & - & 0.99 & 0.99 & 0.99 & 0.98 & 0.79 & 0.002 \\
\hline Intercept & - & $2.3 \pm 1.1$ & $3.5 \pm 1.7$ & $6.3 \pm 2.8$ & $7.0 \pm 3.7$ & $9.8 \pm 6.6$ & $89.3 \pm 18.2^{*}$ \\
\hline Slope & - & $1.0 \pm 0.1$ & $0.98 \pm 0.02$ & $0.96 \pm 0.03$ & $0.96 \pm 0.05$ & $0.9 \pm 0.08$ & $-0.02 \pm 0.2^{*}$ \\
\hline Intercept & - & $15.1 \pm 8.6$ & $15.0 \pm 14.2$ & $12.9 \pm 18.4$ & $-19.4 \pm 18.0$ & $-5.8 \pm 15.0$ & - \\
\hline Slope & - & $0.86 \pm 0.04$ & $0.82 \pm 0.07$ & $0.74 \pm 0.19$ & $0.9 \pm 0.3$ & $0.51 \pm 0.19 \dagger$ & - \\
\hline \multicolumn{8}{|l|}{ Meal frequency } \\
\hline Meals (no./d) & $15.6 \pm 4.2$ & $15.8 \pm 4.4$ & $15.4 \pm 4.5$ & $13.7 \pm 3.1$ & $12.5 \pm 3.0$ & $9.6 \pm 2.0$ & - \\
\hline $\mathrm{R}^{2}$ & - & 0.98 & 0.96 & 0.95 & 0.69 & 0.39 & - \\
\hline Intercept & - & $-0.2 \pm 0.1$ & $-0.7 \pm 1.2$ & $2.7 \pm 1.0$ & $3.4 \pm 2.2$ & $5.1 \pm 2.1^{*}$ & - \\
\hline
\end{tabular}

${ }^{1}$ Feeding behavior data averaged across 10 calves and $3 \mathrm{~d}$.

${ }^{2}$ Regression analysis performed on data summarized by calf over $3 \mathrm{~d}$ of observation.

${ }^{3}$ Calves individually observed for the first $3 \mathrm{~d}$ of wk 14 .

*Intercept values are different from $0(P<0.05)$ and slope values are different from $1(P<0.05)$; †intercept values tend to be different from 0 $(P<0.10)$ and slope values tend to be different from $1(P<0.10)$.

We expected that meal frequency would be reported less reliably with increasing recording interval, because less frequent instantaneous recording is increasingly likely to miss an entire bout of feeding. The weak association of meal time data generated at longer recording intervals with meal time generated by continuous recording may be confusing given the relatively strong association of feeding time at longer recording intervals; however, this result may be explained through consideration of behavior during meal time. Meal time is the summation of daily feeding bouts or meals that contain moments of feeding interspersed with pauses; for example, Appleby et al. (2001) described milk meals as consisting of "sucks" and "gaps." Behavior during a meal varies between calves. Some calves feed consistently with only short pauses, whereas others have only brief occurrences of feeding interspersed with longer pauses (variation between calves is depicted in Figure $1)$. When all moments of feeding are captured, it is possible, by using a meal criterion, to establish start and end times for all meals and thus accurately report a total for meal time, which includes the periods within a meal spent not actually feeding. Missing a brief occurrence of feeding may not greatly reduce an estimate of total feeding time, but may affect the total of intrameal time spent not feeding. This time is a significant portion of meal time; data obtained using continuous recording in the postweaning period indicated that an average of only $42 \%$ of meal time was spent feeding. In comparison, data obtained using instantaneous recording at 2-min intervals showed that an average of $68 \%$ of meal time was spent feeding; thus, intra-meal intervals were greatly underestimated.

Interestingly, the values for slope generated through linear regression decreased with increasing scanning interval for both meal time and meal frequency, whereas values for intercept increased. This suggests that less frequent scans are associated with a greater tendency to underestimate meal time and meal frequency for those calves with longer meal times and more frequent meals per day. This may not be surprising, becausecalves that have more frequent meals are likely to have shorter meals, increasing the possibility of individual meals being entirely missed. Those calves whose meal bouts contain long nonfeeding pauses tend to have greater daily meal time; however, their brief moments of feeding are more easily missed by scans (illustrated in Figure 1) and instantaneous recording may be more likely to underestimate their total meal time.

Selecting which instantaneous recording interval is sufficiently accurate for collection of feeding data by means of linear regression is somewhat subjective. It is unclear what coefficient of determination indicates an adequately strong linear association. Values ranging between 0.9 and 1.0 are considered clearly indicative of a strong relationship (Mitlohner et al., 2001; Endres et al., 2005; Kitts et al., 2011); however, lower values have also been considered adequate. For example, in other validation studies, strong linear association of data sets has been reported with accompanying $\mathrm{R}^{2}$ values of 0.76 (de Passillé et al., 2010) and 0.77 (Burfeind et al., 2011). To further evaluate how closely data obtained from 
instantaneous recording were related to data obtained from continuous recording, tests for whether slope and intercept of the linear model differed from 1 and 0 , respectively, were considered. For all time intervals in which the coefficient of determination was greater than 0.75 , the values generated from linear regression for slope and intercept did not significantly differ from 1 and 0 (Table 1 and Table 2). This indicates that data obtained from instantaneous recording at those time intervals did not greatly over- or underestimate the true values; thus, a strong linear association between instantaneous recording data and continuous data was concurrent with accuracy of the estimates made by instantaneous recording. However, it should be noted that a slope and intercept close to 1 and 0 did not consistently occur when the coefficient of determination was high. For example, milk meal time data obtained using instantaneous recording at intervals of $1 \mathrm{~min}$ and milk feeding time data obtained using instantaneous recording at intervals of $5 \mathrm{~min}$ both had a strong linear association with corresponding data obtained using continuous recording $\left(\mathrm{R}^{2}=0.74\right.$ for meal time, and $\mathrm{R}^{2}$ $=0.76$ for feeding time); however, for the meal time data sets, linear regression yielded slope and intercept values that differed significantly from 1 and 0 (Table $2)$. Thus, no single aspect of linear regression is necessarily indicative of a valid method of data collection.

In the present study, data obtained from instantaneous recording for a particular behavior measure was

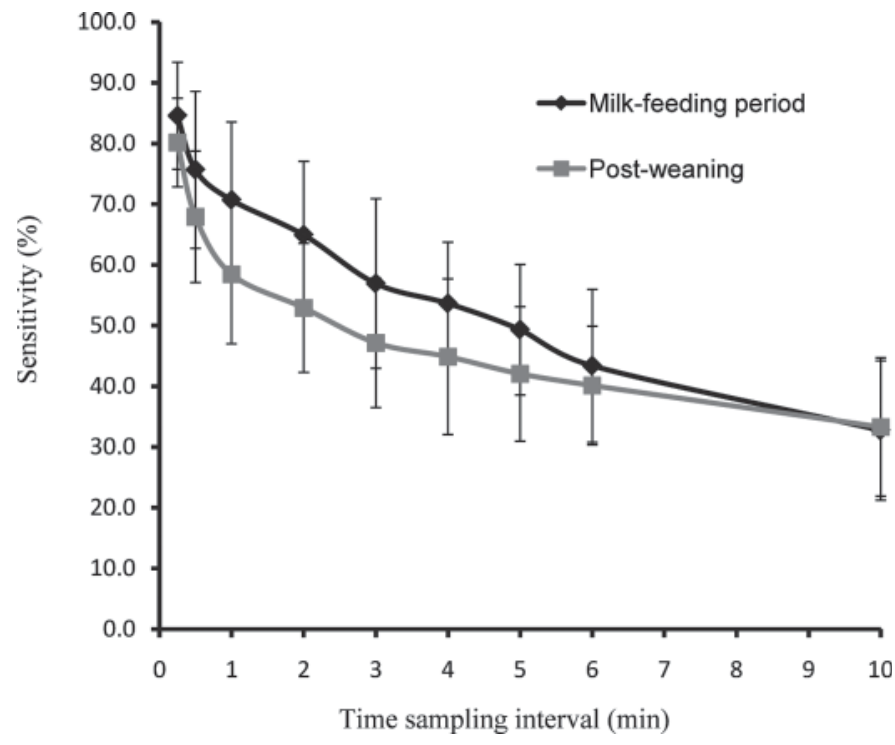

Figure 2. Sensitivity (likelihood that moments of feeding identified by continuous recording were also identified by instantaneous recording) of data obtained from instantaneous recording at different intervals for calves consuming milk ad libitum (milk-feeding period) and calves consuming solid feed (14 wk of age, postweaning). Values are averaged across $3 \mathrm{~d}$ of observation for each of 10 calves. considered to be strongly associated with the continuous recording data when $\mathrm{R}^{2}$ was greater than 0.8 , given that for these $\mathrm{R}^{2}$ values, slope and intercept of the linear model did not differ from 1 and 0 . Data sets were considered to be fairly well associated if $\mathrm{R}^{2}$ was greater than 0.7 and if slope and intercept did not differ from 1 and 0 .

Thus, in both periods, meal time data obtained from instantaneous recording was strongly associated with continuous data $\left(\mathrm{R}^{2}>0.94\right)$ at time sampling intervals of $30 \mathrm{~s}$ or less, and meal frequency was strongly associated $\left(\mathrm{R}^{2}>0.84\right)$ with time sampling intervals of $1 \mathrm{~min}$ or less. Less frequent scanning appeared to suffice for the determination of feeding time; feeding time data obtained from instantaneous recording at intervals of 2 min were strongly associated with data obtained from continuous recording in both periods $\left(\mathrm{R}^{2}>0.93\right)$, and recording at intervals of 5 min provided data with a fair linear association $\left(\mathrm{R}^{2}>0.76\right)$. Although instantaneous recording at intervals of 10 min yielded feeding time averages across calves that were similar to those obtained from continuous recording, the linear association was weak at this interval $\left(\mathrm{R}^{2}=0.002\right)$. Thus, 10 -min scans may suffice for the determination of feeding behavior in heifers or adult cattle but should not be used to characterize feeding time in calves.

Sensitivity for a range of recording intervals is depicted graphically in Figure 2. Values for predictability were similar but slightly lower than sensitivity across sampling intervals $\left(\mathrm{R}^{2}=1.0, \mathrm{y}=0.98 \mathrm{x}-0.93\right)$. As sampling interval increased, instantaneous recording data had an increasing likelihood of not indicating a moment of feeding identified by continuous recording, as well as an increasing likelihood of reporting a moment of feeding not identified by continuous recording. The latter may seem impossible; however, it is explained by the block of time allotted to a positive scan to assess diurnal behavior. Especially at increasing sampling intervals, a high likelihood exists that the block of time allotted to a positive scan may be greater than the actual amount of time the calf spent feeding (illustrated in Figure 1). In contrast to values calculated for sensitivity and predictability, specificity was high across sampling intervals (ranging from $98.7 \%$ for instantaneous recording at intervals of $15 \mathrm{~s}$ to $95.8 \%$ for intervals of $10 \mathrm{~min}$ ) because of the great percentage of time the calf was not feeding according to both continuous recording and instantaneous recording.

The values for sensitivity were lower, even for short recording intervals, than values considered indicative of strong association between data sets in other validation studies. For example, DeVries et al. (2003) reported a sensitivity value of $87 \%$ and phi coefficients of correlation ranging from 0.81 to 0.96 in the validation of 
a feed bunk attendance monitoring system, and described this as a high correlation. In the present study, average phi coefficients of correlation ranged from 0.78 (15-s interval) to 0.36 (10-min interval), indicating consistently poorer correlation of data at the different recording intervals than indicated by linear regression performed on feeding behavior data (Tables 2 and $3)$. The low values for sensitivity as well as phi coefficients of correlation may not be surprising because this analysis considered the accuracy of the instantaneous recording in estimating whether or not feeding occurred on a second-by-second basis, based on time allotted to a positive scan, whereas the linear regression of feeding time and meal characteristics considered only the ability of the instantaneous recording to identify the duration of a meal and the fact that it occurred. Interestingly, despite similar associations between instantaneous recording data and continuous recording data for daily feeding time and meal characteristics in both periods, the sensitivity of instantaneous recording data was consistently lower postweaning. This may be explained by differences in within-meal feeding bouts; milk meals were often observed as consisting of long bouts of sucking interspersed with only short breaks from the teat, whereas postweaning solid feed meals were often observed as consisting of occasional mouthfuls of feed interspersed with long pauses.

The ability of instantaneous recording to accurately describe within-meal feeding bouts is further illustrated in Figure 1. It is clear that feeding bouts characterized by frequent, short moments of feeding interspersed with short breaks are less well represented by data collected from instantaneous recording, whereas feeding bouts that contain longer periods of feeding are represented fairly well. This indicates that time sampling methods for quantifying behavior may not be ideal if withinmeal feeding behavior is of interest; the low phi value of the calf with the weakest correlation indicates that the scanning methods poorly represented feeding behavior within his meals. However, for the purposes of quantifying meal time and meal frequency, this withinmeal variation in behavior may be less of a concern. Although 30-s and 60-s scans may not always represent within-meal patterns well, scans this frequent are relatively unlikely to miss an entire meal or greatly misjudge start and end times of a meal (as indicated by linear regression of meal time and meal frequency for these sampling intervals compared with continuous recording; Tables 2 and 3).

In conclusion, instantaneous recording can be used to effectively obtain feeding behavior data for dairy calves. Although feeding behavior of adult dairy cattle may be accurately quantified through the use of instantaneous recording at intervals as great as $10 \mathrm{~min}$, more frequent sampling intervals appear to be necessary to accurately quantify feeding behavior of young calves, especially when diurnal feeding behavior is of interest. Recommended sampling intervals depend on the feeding behavior of interest; feeding time was reported reasonably accurately by instantaneous recording at intervals between 2 and 5 min, but scans as frequent as $30 \mathrm{~s}$ and 1 min appear necessary to accurately describe meal time and meal frequency, respectively. In general, as meals become shorter and contain longer intra-meal pauses, shorter time sampling intervals are necessary to accurately describe meal patterns.

\section{ACKNOWLEDGMENTS}

We thank the staff and students at the University of Guelph, Kemptville Campus Dairy Education and Research Centre, in particular Mikayla Baxter, Megan Bruce, and Julie Fish. We acknowledge support received from the Natural Sciences and Engineering Research Council of Canada (NSERC, Ottawa, Ontario, Canada). This project was also supported through contributions from the Canadian Foundation for Innovation (CFI, Ottawa, Ontario, Canada), the Ontario Research Fund (Ministry of Research and Innovation, Toronto, Ontario, Canada), and through an Ontario Ministry of Agriculture, Food, and Rural Affairs (OMAFRA, Guelph, Ontario, Canada)/University of Guelph Production Systems research grant.

\section{REFERENCES}

Appleby, M. C., D. M. Weary, and B. Chua. 2001. Performance and feeding behavior of calves on ad libitum milk from artificial teats. Appl. Anim. Behav. Sci. 74:191-201.

Burfeind, O., K. Schirmann, M. A. G. von Keyserlingk, D. M. Weary, and W. Heuwieser. 2011. Technical note: Evaluation of a system for monitoring rumination in heifers and calves. J. Dairy Sci. 94:426-430.

Canadian Council on Animal Care. 2009. Guide to the Care and Use of Farm Animals in Research, Teaching, and Testing. CCAC, Ottawa, ON, Canada.

Chua, B., E. Coenen, J. van Delen, and D. M. Weary. 2002. Effects of pair versus individual housing on the behavior and performance of dairy calves. J. Dairy Sci. 85:360-364.

de Passillé, A. M., M. B. Jensen, N. Chapinal, and J. Rushen. 2010. Technical note: Use of accelerometers to describe gait patterns in dairy calves. J. Dairy Sci. 93:3287-3293.

de Paula Vieira, A., V. Guesdon, A. M. de Passillé, and M. A. Grafin. 2008. Behavioural indicators of hunger in dairy calves. Appl. Anim. Behav. Sci. 109:180-189.

DeVries, T. J., M. A. G. von Keyserlingk, D. M. Weary, and K. A. Beauchemin. 2003. Technical note: Validation of a system for monitoring feeding behavior of dairy cows. J. Dairy Sci. 86:3571-3574.

Endres, M. I., T. J. DeVries, M. A. G. von Keyserlingk, and D. M. Weary. 2005. Short communication: Effect of feed barrier design on the behavior of loose-housed lactating dairy cows. J. Dairy Sci. 88:2377-2380.

Gibb, D. J., K. S. Schwartzkopf-Genswein, J. M. Stookey, J. J. McKinnon, D. L. Godson, R. D. Wiedmeier, and T. A. McAllister. 2000. Effect of a trainer cow on health, behavior, and performance of newly weaned beef calves. J. Anim. Sci. 78:1716-1725. 
Haley, D. B., D. W. Bailey, and J. M. Stookey. 2005. The effects of weaning beef calves in two stages on their behavior and growth rate. J. Anim. Sci. 83:2205-2214.

Jensen, M. B. 2009. Milk meal pattern of dairy calves is affected by computer-controlled milk feeder set-up. J. Dairy Sci. 92:29062910.

Jensen, M. B., and M. Budde. 2006. The effects of milk feeding method and group size on feeding behavior and cross-sucking in grouphoused dairy calves. J. Dairy Sci. 89:4778-4783.

Kitts, B. L., I. J. H. Duncan, B. W. McBride, and T. J. DeVries. 2011. Effect of the provision of a low-nutritive feedstuff on the behavior of dairy heifers limit fed a high-concentrate ration. J. Dairy Sci. 94:940-950.

MacDonald, P. D. M., and P. E. J. Green. 1988. User's Guide to Program MIX: An interactive program for fitting mixtures of distributions. Release 2.3, January 1988. Ichthus Data Systems, Hamilton, Ontario, Canada.
Martin, P., and P. Bateson. 2007. Measuring Behaviour: An Introductory Guide. Cambridge University Press, Cambridge, UK.

Mitlöhner, F. M., J. L. Morrow-Tesch, S. C. Wilson, J. W. Dailey, and J. J. McGlone. 2001. Behavioral sampling techniques for feedlot cattle. J. Anim. Sci. 79:1189-1193.

Rushen, J., and A. M. de Passillé. 1995. The motivation of non-nutritive sucking in calves, Bos taurus. Anim. Behav. 49:1503-1510.

SAS Institute. 2008. SAS version 9.2. SAS Institute Inc., Cary, NC.

Svensson, C., and P. Jensen. 2007. Short communication: Identification of diseased calves by use of data from automatic milk feeders. J. Dairy Sci. 90:994-997.

Svensson, C., and P. Liberg. 2006. The effect of group size on health and growth rate of Swedish dairy calves housed in pens with automatic milk-feeders. Prev. Vet. Med. 73:43-53. 